\title{
NOTAS EM HOMENAGEM AO PROFESSOR ANTÔNIO BARROS DE CASTRO SEMINÁRIO: O BRASIL NO ESPELHO DA CHINA: AS REFLEXÕES DE BARROS DE CASTRO*
}

\section{Carlos Américo Pacheco ${ }^{a}$}

Quero iniciar esta seção com um sincero agradecimento aos professores Fernando Nogueira da Costa e Júlio Gomes de Almeida. Eles viabilizaram, com suas contribuições, que este seminário se realizasse. Quero prestar meu agradecimento especial ao professor Fernando Costa, por ter preparado uma notável intervenção que ele iria proferir aqui hoje. Infelizmente, o professor Fernando sofreu ontem um acidente doméstico que o impede de estar entre nós. Vou me valer de suas notas, no que couber, e vamos disponibilizá-las a todos os interessados.

Aos mais curiosos, remeto ao blog do professor Fernando Costa (http://fernandonogueiracosta.wordpress.com), onde há uma foto da fatídica estante de livros que foi destroçada por ele na madrugada passada.

Com tantas desventuras, pode parecer que vamos ter de providenciar uma proteção adicional para os riscos associados a este seminário. Mas digo a vocês, com a convicção de quem pode conviver com muitos dos palestrantes que nos vão nos dar a graça de sua presença, que o que nos move aqui é algo mais poderoso: é a curiosidade intelectual, é saber mais, é interpretar o mundo. Esse tipo de postura será sempre nosso guia e nossa mais poderosa proteção.

Todos sabem que essa é uma seção de homenagem. Um reconhecimento muito especial. Vamos prestar aqui nossa sincera homenagem a uma pessoa ímpar, absolutamente admirável: o professor Antônio Barros de Castro, que convidamos, junto com o embaixador Amaury Porto, a abrir este ciclo de debates sobre a China na UNICAMP. Iríamos, como todos sabem, contar com sua presença aqui, no dia 25 de agosto passado. E seria, com certeza, um debate rico, inspirador, como costumavam ser as palestras do professor Castro.

Foi uma perda grande. O professor Castro iria atualizar sua reflexão acerca de como o deslocamento do centro de gravidade da economia mundial para a Ásia, em particular

\footnotetext{
* Este texto foi originalmente apresentado no seminário "O Brasil no espelho da China: as reflexões de Barros de Castro", promovido pelo Instituto de Economia da Universidade Estadual de Campinas (UNICAMP) no dia 06 de outubro de 2011. Para fins de publicação nesta edição da REC, o texto original revisto e editado visando se adequar ao padrão textual e gráfico desta publicação.

a Doutor em Economia pela UNICAMP, professor do Instituto de Economia da UNICAMP e atual reitor do Instituto Tecnológico de Aeronáutica (ITA).
} 
para a China, repercutiria no desenvolvimento da economia brasileira. Vamos debater esta sua tese na seqüência, a partir da intervenção do professor Julinho. Mas vamos, antes de mais nada, render uma merecida homenagem ao professor Barros de Castro.

O currículo do professor Barros de Castro fala por si: formou-se em economia pela Universidade do Brasil, atual Universidade Federal do Rio de Janeiro (UFRJ). Em 1972 e 1973, foi professor visitante na Universidade do Chile; de 1973 a 1974, trabalhou na Universidade de Cambridge. Foi professor da UNICAMP na década de 1970, onde defendeu seu doutorado em 1977. De 1980 a 2003, foi professor titular do Instituto de Economia da UFRJ, onde recebeu o título de professor emérito. Foi professor visitante também na Universidade da Califórnia em Berkeley entre 1999 e 2003 e na Universidade de Oxford, em 2004, além de participar do Institute for Advanced Study da Universidade de Princeton. Foi presidente (1992-1993), diretor (2004-2007) e assessor da presidência do Banco Nacional do Desenvolvimento Econômico e Social (BNDES).

Mas seu currículo formal não reflete a totalidade de sua contribuição, de sua maneira de pensar e de seus interesses variados.

O professor Castro era um intelectual na expressão plena do termo, que nos fará muita falta, pelo brilho, pela originalidade, pela forma de nos instigar, aos mais velhos e à nova geração, a pensar de forma criativa os problemas que tem pela frente. A pensar o Brasil... e a pensar a China, pois, como ele nos ensinava, não há como pensar o futuro do Brasil, sem ao menos tentar interpretar, decifrar, isto que é e será a China de nossos tempos.

Eu tive o enorme azar de ser mais novo, confesso que bem mais novo, que Fernando Mineiro e Julinho. Não fui aluno, infortunadamente, aqui na UNICAMP, do professor Antônio Barros de Castro.

Tive professores brilhantes, nos os cito todos, porque vou esquecer de algum. E todos sabem, que entre artistas e professores a vaidade é um atributo que convive, cotidianamente, com o brilho.

Tive muito azar em não ter sido aluno do professor Novais, com suas sextilhas de Santo Antão; do professor Carlos Lessa, com sua ironia e esplêndida exposição do pensamento de Schumpeter. E, em especial, não tive a oportunidade de ser aluno do professor Castro, reconhecidamente, na opinião de seus alunos, um dos professores mais brilhantes que passou pelo IE da UNICAMP. Vejam neste sentido a perspicaz comparação que o Fernando Mineiro faz, na apresentação que está no seu blog e vai ser distribuída, dos discursos e dos recursos didáticos de Lessa, com suas metáforas humorísticas ("tão lucrativo como plantação irrigada de coca") e da linguagem épica do Castro, como "tomar as rédeas da história" ou "transbordar para o futuro". 
Há muitas maneiras de falar do professor Castro. Mas há uma frase no depoimento do professor Antônio Barros de Castro no segundo volume do Livro Conversas com economistas brasileiros, coordenado pelo Guido Mantega, que é lapidar. Acho que se aplica com perfeição a ele mesmo. É a definição do Castro do que é produzir do ponto de vista intelectual. Ele diz: "O que produz é a imaginação (...) A lógica e os dados servem para questionar". Eu inverti propositadamente a ordem da frase, porque para mim este é o professor Castro que conheci. Aliás, diz ele: "Na minha visão (por influência de Popper), o mundo, o 'faro' e a sensibilidade contam muito para o avanço do conhecimento".

Há nesse livro um depoimento pessoal impressionante. De um grande intelectual. De alguém que vai para além da fronteira convencional do interesse pela economia.

Evidente o Castro é um economista. Economista de livros consagrados, como Introdução à Economia: Uma abordagem estruturalista, em co-autoria com Carlos Lessa, um best-seller, com cerca de meio milhão de livros vendidos, 7 Ensaios sobre a Economia Brasileira, O Capitalismo Ainda é Aquele e A Economia Brasileira em Marcha Forçada, em parceria com Francisco Eduardo Pires de Souza.

Mas seu interesse pela filosofia, pela história e, mais recentemente, pela administração, pelo interesse crescente na concepção de estratégia, também marcaram sua forma singular de pensar.

Como iria tentar explicar o professor Fernando Costa, é muito difícil enquadrar o professor Castro numa corrente específica do pensamento econômico. Há evidentes influências nele de autores como Marx, Schumpeter e Keynes. Vou usar aqui uma frase de sua filha Lavínia Barros de Castro, publicada nas últimas semanas ${ }^{1}$, que acho que resume bem estas diversas influências. Diz ela sobre seu pai:

Leu e deu muito tempo aulas sobre Marx. Um leitor atento perceberá facilmente, em muitos de seus artigos, essa influência. Meu pai considerava seu estudo sobre a economia da cana-de-açúcar um de seus melhores trabalhos. Nele, se encontra o seu lado historiador. Tinha também um lado profundamente keynesiano, digamos, era o seu lado policy. Sempre acreditou na mão visível do Estado e no perigo de deixar os mercados sozinhos. Admirava Minsky, mas o seu objeto maior de estudo era o "lado real da economia". Um dos autores mais influentes de sua obra era Schumpeter, pela ênfase no caráter inovador do capitalismo e na compreensão da sua dinâmica. Era quase um schumpeteriano, mas como não descartava os demais autores, não se podia exatamente dizer isso. Estudou muito os velhos institucionalistas e dava grande papel às instituições e convenções. Entre os institucionalistas, Hirschmann, era seu predileto.

\footnotetext{
${ }^{1}$ Depoimento publicado na página eletrônica da Associação Nacional dos Centros de Pós-Graduação em Economia (ANPEC). Disponível em: <http://www.anpec.org.br/castro.htm\#>. Acesso em: 06 out. 2012. (Nota do editor)
} 
O que marcou o professor Castro foi a originalidade e uma forma diferente de pensar. De identificar aspectos que os outros não davam atenção. Era mais que um heterodoxo, como salientaram muitos de seus colegas. José Serra o descreveu, numa pequena nota ${ }^{2}$ dias atrás, da seguinte forma:

"Castro bebeu na fonte cepalina dos anos sessenta, então bem heterodoxa, mas rapidamente mostrou-se um heterodoxo entre os cepalinos, como revelaram (seus) ensaios. Tinha uma enorme capacidade de estudo, muita curiosidade pelos fatos e por idéias de outros. Sabia expor as suas de forma didática, atraente e respeitosa, mas enfática, mesmo quando distantes do pensamento dos interlocutores. Raramente se envolvia mais a fundo em discussões sobre a conjuntura da economia - seu foco privilegiado sempre foi o médio e o longo prazos e a análise das questões estruturais"

Essa originalidade, esse inconformismo, o levava a ver fatos e a pensar muitas vezes de forma muito diferente que seus colegas, por mais heterodoxos que fossem. Vou ficar num exemplo. Talvez o mais polêmico de todos. Seu ensaio no livro A Economia Brasileira em Marcha Forçada vai na contra-mão de quase tudo o que se escreveu sobre o II Plano Nacional do Desenvolvimento (PND).

Quem quer que tenha estudado este período da história recente do Brasil conhece e admira a brilhante análise que Carlos Lessa fez sobre o que chamou de "Sonho e Fracasso". Aqui, nesta casa, se produziram muitas análises bem feitas sobre a inconsistência da política econômica inspirada na idéia de "ilha de prosperidade", a exemplo de textos já clássicos de Luiz Gonzaga Belluzzo e Luciano Coutinho; do Paulo Davidoff, do Ricardo Carneiro, para citar alguns.

Mas o professor Castro viu o que talvez não tenhamos visto. Pouco preso às conjunturas, profundamente estruturalista e um economista do mundo real, ele foi buscar outra interpretação dos impactos do II PND, ou do ele chamou de "da mutação que seria promovida no Brasil pela estratégia de 74". Não que não concordasse com as consequências macroeconômicas do endividamento e que não fosse um crítico ácido do autoritarismo, mas queria entender que rupturas haviam sido postas em marcha com o II PND e que permitiriam ao Brasil trilhar novos caminhos, depois de sanada a crise da dívida.

Há ali, ele cita, uma inspiração forte do Hirschman, para entender o que ele chamava de "descontinuidades e rupturas qualitativas". Vejamos quão heterodoxas são as interpretações de do professor Castro sobre este período. Diz ele:

\footnotetext{
${ }^{2}$ SERRA, J. Castro: inteligência e método. Blog do José Serra. 27/08/2011. Disponível em: <http://www.joseserra.com.br/archives/1413>. Acesso em: 06 out. 2012. (Nota do editor)
} 
No quarto de século que vai de 1948 a 73, o crescimento da indústria foi bastante rápido. Este crescimento não parecia contudo destinado a reproduzir aqui uma estrutura industrial completa e moderna. Setores tais como as indústrias de base e de bens de capital revelaram-se incapazes de assumir o peso e funções que lhes correspondem nas estruturas industriais avançadas. (...) Conseqüentemente, não obstante todo o crescimento industrial pregresso, não se havia de fato superado aquilo que a CEPAL denominou de etapa "difícil" da industrialização. Em suma, o crescimento industrial havia sido enorme, mas, ao topar com a barreira das indústrias "difíceis", ladeara o obstáculo, prosseguindo sob a forma de uma expansão predominantemente horizontal (...) O crescimento veloz, horizontal, e tecnologicamente passivo dos anos 1968/73 teve abrupto fim em 1974. Dali por diante, em marcha forçada, a economia subiria a rampa das indústrias capital- intensivas e tecnológico-intensivas. (CASTRO, 1985)

\section{E diz mais:}

Combinando-se as duas ordens de considerações, vemos que a economia dispõe presentemente de um avantajado núcleo (energia, metalurgia, química e bens de capital) que, por sua versatilidade, pode, em princípio, ser posto a serviço de diferentes estratégias, e de um setor de bens "de luxo" com crescente acesso ao mercado externo. Ambas as mudanças apontam numa direção: a evolução registrada no último decênio tendeu a descondicionar o dinamismo da economia, do perfil da demanda interna. Evidentemente, o surgimento de uma constelação de institutos de pesquisa, empresas de engenharia, de consultoria, etc., em maior ou menor medida capacitados a recondicionar e recriar processos técnicos e produtos, ao elevar a capacidade de modelagem da própria oferta, não fez senão reforçar a proposição anterior. (...) Os argumentos anteriores sugerem que, finda a custosa marcha forçada iniciada em 1974 (...) o país conta, presentemente, com uma nova base - e um amplo campo de possibilidades. (CASTRO, 1985)

Evidente que não faltaram críticas a este ensaio. De um lado aqueles, mais liberais, que só viam os custos associados a uma industrialização ineficiente, protecionista e estatizante. De outro, os que criticavam a megalomania do II PND e a miopia de sua estratégia, num mundo já em crise.

Castro via de outra forma: via que a mudança da estrutura produtiva provocada pela "marcha forçada" empurrava o Brasil para frente. Desbalanceado e de forma descontínua, como é, aliás, sempre o desenvolvimento, essas mudanças alteravam qualitativamente a trajetória brasileira anterior. Não há como não dar razão a ele, por mais que também exista racionalidade em entender os custos associados a esta trajetória.

Duas coisas chamam atenção aqui:

A primeira é não ter medo de ir contra a corrente, contra o pensamento convencional. Esteja ele à direita, ou à esquerda. Ver coisas que os outros não vêem. E se posicionar de forma pública e aberta neste debate. Isso exige coragem intelectual. 
A segunda é a obsessão pelo longo prazo, pelas mudanças estruturais, da perspectiva do desenho da estrutura produtiva. Isso nos anos 1980, num momento da vida nacional que a conjuntura e a macroeconomia eram tudo, porque parecia que não tínhamos longo prazo, no penoso ajuste que fizemos ao longo da década, na busca da estabilização.

Nos anos recentes, analisando as consequências das transformações dos anos 1990 e as melhores estratégias para o Brasil, o professor Barros de Castro nos fez novamente pensar de forma não ortodoxa e nada convencional sobre estas questões, nos seus vários escritos sobre a trajetória brasileira, como em: "A Capacidade de Crescer” (1996), “A Reestruturação Industrial Brasileira” (2001), "El segundo Catch-up Brasileño: Características y Limitaciones” (2003), "Da Semi-estagnação ao Crescimento num Mercado Sino-cêntrico" (2007).

Seu olhar sobre as estratégias das empresas e sobre o ajuste dos anos 1990 também se distanciava da vala comum. Enquanto, de um lado, alguns só viam modernização passiva e uma especialização regressiva, muitos de nós entre eles; e do outro lado, havia gente que glorificava os êxitos da abertura e do aumento da produtividade, o professor Castro via avanços, no que chamou de segundo catch-up da indústria brasileira. Mas via também riscos, especialmente relacionados às estratégias pouco inovadora das empresas, presas apenas à mudança de suas funções produtivas. Via que a indústria havia passado bem pelo teste da abertura, mas via também os limites derivados das respostas espontâneas das empresas e de políticas industriais presas ao passado, que olhavam o Brasil pelo "espelho retrovisor", como ele gostava de afirmar.

Lembro-me claramente que, em meados de 2006, logo após o anúncio da nova Política Industrial brasileira (PITCE), num seminário exatamente sobre política industrial, ele me disse: "estamos fritos, voltamos a crescer". Eu fiquei curioso e ele explicou: "vamos esquecer a política industrial". O significado era isso: os interesses presentes, já estabelecidos em nossa estrutura industrial, muitas vezes nos impedem de avançar. $\mathrm{O}$ crescimento funciona, neste caso, como um anestésico. Mudar a estrutura produtiva, avançar, muitas vezes passa ao largo do interesse concreto das lideranças industriais já estabelecidas. Ele já havia escrito isso no livro A Economia Brasileira em Marcha Forçada, quando alertava que a internalização da indústria de insumos básicos e de máquinas e equipamentos, por razões de preço, de qualidade e de garantia de abastecimento, não era do interesse imediato das empresas aqui instaladas, quer nacionais, que estrangeiras.

A questão que o animava nos anos recentes, animava sempre para dizer a verdade, e por isso a relevância da China, era que rumos deveríamos dar à indústria brasileira. Questão difícil, como dizia, porque “após o re-emparelhamento industrial dos anos 1990, seria difícil imaginar, que a economia brasileira pudesse (possa) ingressar numa divisão internacional do trabalho de corte clássico", como mera provedora de bens primários. 
Nem caberia este papel, ao menos em nossa aspiração nacional de desenvolvimento, nem nos caberia disputar no mesmo terreno da indústria chinesa.

Sua energia estava dedicada a identificar um caminho contraposto ao determinismo, digamos "ricardiano", de que vamos ter uma nova divisão internacional do trabalho em que cabe à China o papel de provedora de bens industriais; à Índia, o papel de fornecedora de serviços; à Rússia, o papel de produtora de energia (petróleo e gás); e a nós, o papel de grande provedor de alimentos, como chama atenção Fernando Nogueira na apresentação que nos iria fazer.

Em 2007, Castro escreveu: "Em tais circunstâncias, a economia brasileira começa a pagar um preço por haver desenvolvido e, em boa medida, consolidado (nos anos 1990), um sistema industrial altamente diversificado. Num mercado cada dia mais aberto, e crescentemente sino-cêntrico, a indústria brasileira passava a demandar novos rumos" (p. 27).

Seu ponto de partida, segundo Fernando Nogueira, era de que «a economia brasileira dispõe de sistema industrial cuja diversidade só tem paralelo, entre as economias emergentes, na China e na Índia. Este sistema industrial brasileiro foi em boa medida montado muito antes da emergência chinesa. A estrutura industrial congelada não impediu que as empresas se renovassem, intensamente, e sob vários pontos de vista. Ao contrário, em diversos ramos isto permitiu que pelo menos as maiores e melhores empresas, reconhecidamente, atingissem o estado das artes internacional".

Sua maneira de pensar sobre estes problemas não era convencional. Porque, se de um lado, sempre estava propenso a examinar que setores, que atividades seriam aquelas que contariam com Efeitos-China positivos; também estava voltado a identificar as empresas de um ponto de vista mais amplo, em seu mix de atividades, em suas "folgas" e "carências" no uso de seus recursos. Ou seja, "de como extrair novos e diferentes "serviços", dos recursos existentes no âmbito das empresas".

Exprimia otimismo sobre o Brasil, pelo fato de estarmos acumulando capacitação tecnológica há décadas. Um otimismo sempre moderado pelo desafio de ter de rever, aprofundar e desenvolver nossas antigas e mesmo as novas soluções para podermos passar a um novo estágio de desenvolvimento.

A pergunta era qual a estratégia, no sentido de grandes escolhas, que deveríamos fazer no contexto de um mercado mundial sino-cêntrico.

Como ele gostava de afirmar, o Brasil teria de se reinventar para ser bem-sucedido em uma economia mundial radicalmente mudada pela China. Diante da competição chinesa, ele afirmou em entrevista recente, "não adianta proteger setores industriais para que eles fiquem um pouco mais sofisticados, porque os asiáticos fazem o mesmo com maior velocidade". Ou ainda, de forma mais enfática: "Mesmo se o câmbio e o 
custo Brasil forem neutros, boa parte da indústria brasileira não é competitiva porque o sistema industrial chinês é mais eficiente"3.

Teríamos que saber usar os recursos gerados pelo boom de matérias primas para desenvolver produtos originais, novos setores, novas funções empresariais. Uma tarefa difícil, mas um desafio enorme que ele sempre nos devolvia, perguntando o que considerávamos que seriam nossas grandes apostas, nossas melhores opções.

Para finalizar, gostaria de indicar que o professor Antônio Barros de Castro era um intelectual de grandes insights, no sentido que apontei ao início de que "o que produz é a imaginação". Sua presença entre nós despertava sempre o desejo de ouvi-lo, de refletir sobre estes seus insights. Sua obra nos serve como inspiração, sua reflexão sobre o Brasil e a China marcou a criação de vários centros de estudos, a começar da própria UFRJ, e com certeza marcarão os passos que daremos aqui na UNICAMP.

\section{REFERÊNCIAS BIBLIOGRÁFICAS}

CASTRO, A. B. Da semi-estagnação ao crescimento no mercado sino- cêntrico. Rio de Janeiro, 2007, mimeo.

CASTRO, A. B. El segundo Catch-up Brasileño: Características y Limitaciones. Revista de la Cepal, n. 90, agosto, 2003.

CASTRO, A. B. A reestruturação industrial brasileira nos anos 1990. Uma interpretação. Revista de Economia Política, v. 21, n. 3, 2001.

CASTRO, A. B. A capacidade de crescer como problema. In: VELLOSO, J. P. R. (Coord.) O Real, O Crescimento e as Reformas. Rio de Janeiro: José Olimpyo Editora, 1996.

CASTRO, A. B. "Ajustamento X transformação: a economia brasileira de 1974 a 1984”. In: CASTRO, A. B.; SOUZA, F. E. P. A economia brasileira em marcha forçada. Rio de Janeiro: Paz e Terra, 1985.

\footnotetext{
${ }^{3}$ Trechos de entrevista concedida à jornalista Claudia Antunes, da Folha de São Paulo, no dia 11 de abril de 2011. Disponível em: <http://wwwl.folha.uol.com.br/mercado/963141-brasil-tem-de-se-reinventar-para-tratar-com-a-china-diz-antonio-de-castro.shtml>. Acesso em 06 out. 2012.
} 